\title{
A Review of Carbon Fiber
}

\author{
Durgesh Dashrath Divate \\ B.E., Department of Mechanical Engineering, Fr. C. Rodrigues Institute of Technology (Mumbai University),
}

Navi Mumbai, India

\begin{abstract}
Among the major developments in materials in recent year are composite materials, as they offer several outstanding properties as compared to several conventional materials. Composite materials have found increasingly wide applications in aircraft, space vehicles, offshore structures, electronics, automobiles, boats, and sporting goods. Today composite materials have changed all the material engineering. The evolution of composite materials has given an opportunity to various designers to use new and better materials resulting in cost reduction, increase in efficiency and better utilization of available resources. Research and development activities in this area are concerned with improving strength, toughness, stiffness, resistance to high temperature and reliability in service. Many composites materials are composed of just two phases; matrix and dispersed phase.
\end{abstract}

Keywords: aircraft, space vehicles, offshore structures, electronics, automobiles, composite materials, strength, toughness, stiffness, research.

\section{INTRODUCTION}

Carbon fibers or carbon fibres (alternatively CF, graphite fiber or graphite fibre) are fibers about 5-10 micrometres in diameter and composed mostly of carbon atoms. Carbon fibers have several advantages including high stiffness, high tensile strength, low weight, high chemical resistance, high temperature tolerance and low thermal expansion. These properties have made carbon fiber very popular in aerospace, civil engineering, military, and motorsports, along with other competition sports. However, they are relatively expensive when compared with similar fibers, such as glass fibers or plastic fibers.

To produce a carbon fiber, the carbon atoms are bonded together in crystals that are more or less aligned parallel to the long axis of the fiber as the crystal alignment gives the fiber high strength-to-volume ratio (making it strong for its size). Several thousand carbon fibers are bundled together to form a tow, which may be used by itself or woven into a fabric. Carbon fibers are usually combined with other materials to form a composite. When combined with a plastic resin and wound or molded it forms carbon-fiber-reinforced polymer (often referred to as carbon fiber) which has a very high strength-to-weight ratio, and is extremely rigid although somewhat brittle. However, carbon fibers are also composited with other materials, such as graphite, to form carbon-carbon composites, which have a very high heat tolerance.

\subsection{Properties of composite}

1. $\quad$ High Strength to weight ratio

Strength of a material is the force per unit area at failure, divided by its density. Any material that is strong and light has a favourable Strength/Weight ratio. Materials such as Aluminium, titanium, magnesium, Carbon and glass fiber, high strength steel alloys all have good strength to weight ratios. It is not surprising that Balsa wood comes in with a high strength to weight ratio.

2. Rigidity

Rigidity or stiffness of a material is measured by its Young Modulus and measures how much a material deflects under stress. Carbon fiber reinforced plastic is over 4 times stiffer than Glass reinforced plastic, almost 20 times more than pine, 2.5 times greater than aluminium.

3. Fatigue Resistance

Resistance to Fatigue in Carbon Fiber Composites is good. However when carbon fiber fails it usually fails catastrophically without significant exterior signs to announce its imminent failure.

4. Good tensile strength but Brittle

Tensile strength or ultimate strength, is the maximum stress that a material can withstand while being stretched or pulled before necking, or failing.

5. Low coefficient of thermal expansion

This is a measure of how much a material expands and contracts when the temperature goes up or down.

6. Hardness

Hardness is described as resistance to surface indentation of the material. Graph explains the effect of glass fiber and carbon fiber reinforcements on the micro hardness of the hybrid composites. 


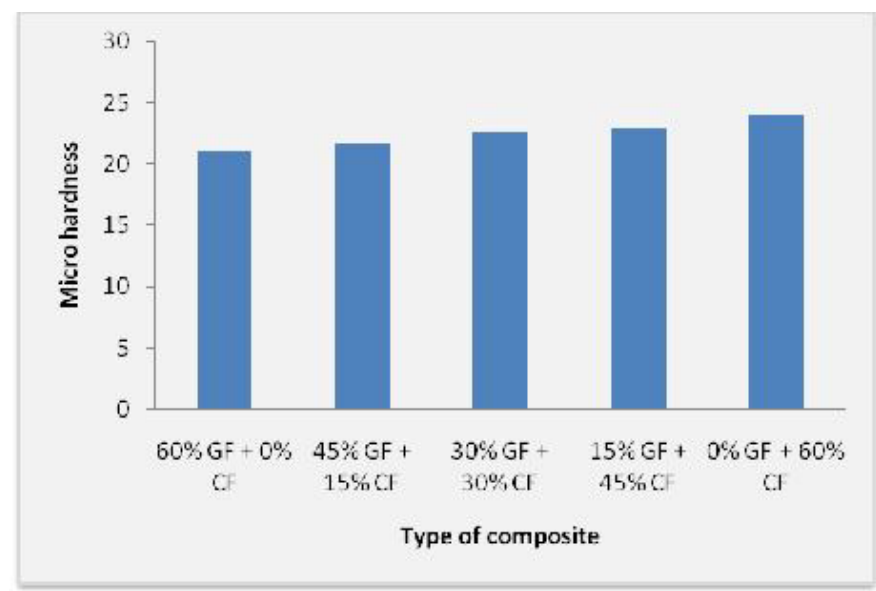

The carbon fiber reinforced epoxy composite exhibits higher micro hardness as compared to other two composites. The $60 \%$ carbon fiber reinforced composites shows $14.29 \%$ increase in the micro hardness as compared to $60 \%$ glass fiber reinforced composites and 23 increase in the micro hardness with that of $30 \%$ glass fiber and $30 \%$ carbon fiber reinforced hybrid composite. The increase in the hardness in the composites is the indication of good bonding between the matrix and the reinforcement materials.

\subsection{India gets first carbon fiber plant}

May $9^{\text {th }}$ 2010, Former President Dr A P J Abdul Kalam on Sunday inaugurated the country's first carbon fibre manufacturing facility. The Rs 250-crore set up will produce lightweight material for use in defence, aerospace and infrastructure - under technology transfer from the Council of Scientific and Industrial Research's (CSIR) National Aerospace Laboratory (NAL), which had developed the ultra-light material for the Light Combat Aircraft.

\section{MANUFACTURING PROCESS OF CARBON FIBER}

The raw material used to make carbon fiber is called the precursor. About $90 \%$ of the carbon fibers produced are made from polyacrylonitrile (PAN). The remaining 10\% are made from rayon or petroleum pitch. All of these materials are organic polymers, characterized by long strings of molecules bound together by carbon atoms. The exact composition of each precursor varies from one company to another and is generally considered a trade secret.

During the manufacturing process, a variety of gases and liquids are used. Some of these materials are designed to react with the fiber to achieve a specific effect. Other materials are designed not to react or to prevent certain reactions with the fiber. As with the precursors, the exact compositions of many of these process materials are considered trade secrets. The process for making carbon fibers is part chemical and part mechanical. The precursor is drawn into long strands or fibers and then heated to a very high temperature with-out allowing it to come in contact with oxygen. Without oxygen, the fiber cannot burn. Instead, the high temperature causes the atoms in the fiber to vibrate violently until most of the non-carbon atoms are expelled. This process is called carbonization and leaves a fiber composed of long, tightly inter-locked chains of carbon atoms with only a few non-carbon atoms remaining.

Typical sequence of operations used to form carbon fibers from polyacrylonitrile (PAN)

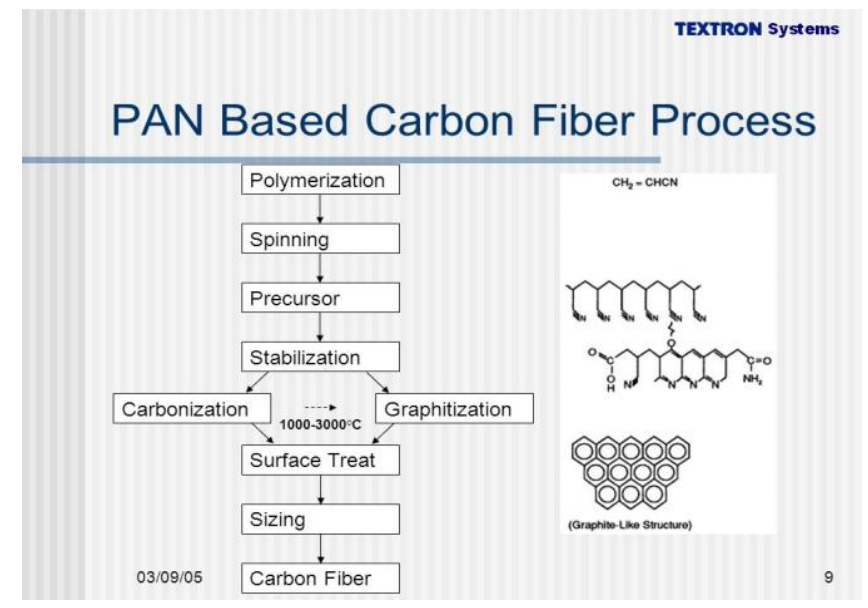




\subsection{Spinning}

Acrylonitrile plastic powder is mixed with another plastic, like methyl acrylate or methyl methacrylate, and is reacted with a catalyst in a conventional suspension or solution polymerization process to form a polyacrylonitrile plastic.

The plastic is then spun into fibers using one of several different methods. In some methods, the plastic is mixed with certain chemicals and pumped through tiny jets into a chemical bath or quench chamber where the plastic coagulates and solidifies into fibers. This is similar to the process used to form polyacrylic textile fibers. In other methods, the plastic mixture is heated and pumped through tiny jets into a chamber where the solvents evaporate leaving a solid fiber. The spinning step is important because the internal atomic structure of the fiber is formed during this process.

The fibers are then washed and stretched to the desired fiber diameter. The stretching helps align the molecules within the fiber and provide the basis for the formation of the tightly bonded carbon crystals after carbonization.

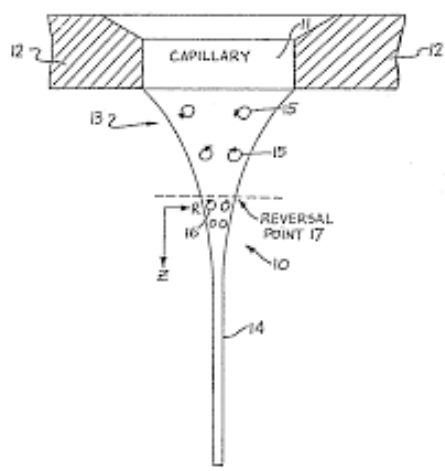

Fig. 2.1. Spinning

\subsection{Stabilizing}

Before the fibers are carbonized, they need to be chemically altered to convert their linear atomic bonding to a more thermally stable ladder bonding. This is accomplished by heating the fibers in air to about $390-590^{\circ} \mathrm{F}\left(200-300^{\circ} \mathrm{C}\right)$ for 30-120 minutes. This causes the fibers to pick up oxygen molecules from the air and rearrange their atomic bonding pattern. The stabilizing chemical reactions are complex and involve several steps, some of which occur simultaneously. They also generate their own heat, which must be controlled to avoid overheating the fibers. Commercially, the stabilization process uses a variety of equipment and techniques. In some processes, the fibers are drawn through a series of heated chambers. In others, the fibers pass over hot rollers and through beds of loose materials held in suspension by a flow of hot air. Some processes use heated air mixed with certain gases that chemically accelerate the stabilization.

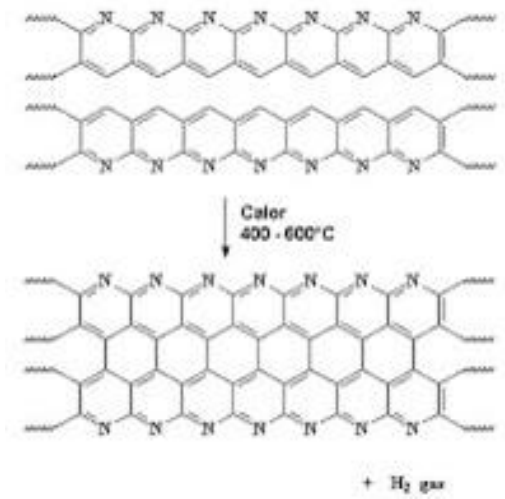

Fig.2. Stabilizing

\subsection{Carbonizing}

Once the fibers are stabilized, they are heated to a temperature of about $1,830-5,500^{\circ} \mathrm{F}\left(1,000-3,000^{\circ} \mathrm{C}\right)$ for several minutes in a furnace filled with a gas mixture that does not contain oxygen. The lack of oxygen prevents the fibers from burning in the very high temperatures. The gas pressure inside the furnace is kept higher than the outside air pressure and the points where the fibers enter and exit the furnace are sealed to keep oxygen from entering. As the fibers are heated, they begin to lose their non-carbon atoms, plus a few carbon atoms, in the form of various gases including water vapor, ammonia, carbon monoxide, carbon dioxide, hydrogen, nitrogen, and others. As the non-carbon atoms are expelled, the remaining carbon atoms form tightly bonded carbon crystals that are aligned more or less parallel to the long axis of the fiber. In some processes, two furnaces operating at two different temperatures are used to better control 
the rate of heating during carbonization.

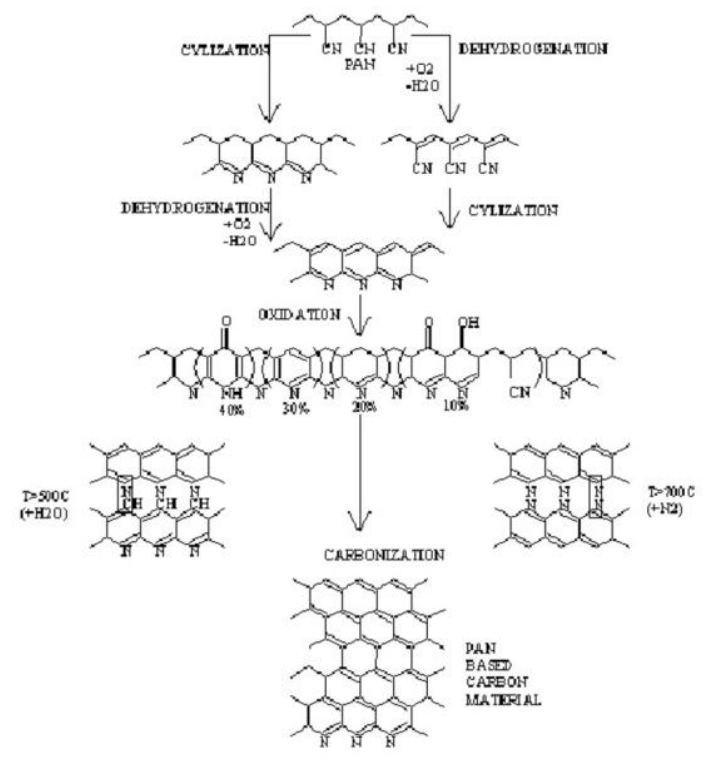

Fig. 2.3. Carbonizing

\subsection{Treating the Surface}

After carbonizing, the fibers have a surface that does not bond well with the epoxies and other materials used in composite materials. To give the fibers better bonding properties, their surface is slightly oxidized. The addition of oxygen atoms to the surface provides better chemical bonding properties and also etches and roughens the surface for better mechanical bonding properties. Oxidation can be achieved by immersing the fibers in various gases such as air, carbon dioxide, or ozone; or in various liquids such as sodium hypochlorite or nitric acid. The fibers can also be coated electrolytically by making the fibers the positive terminal in a bath filled with various electrically conductive materials. The surface treatment process must be carefully controlled to avoid forming tiny surface defects, such as pits, which could cause fiber failure.

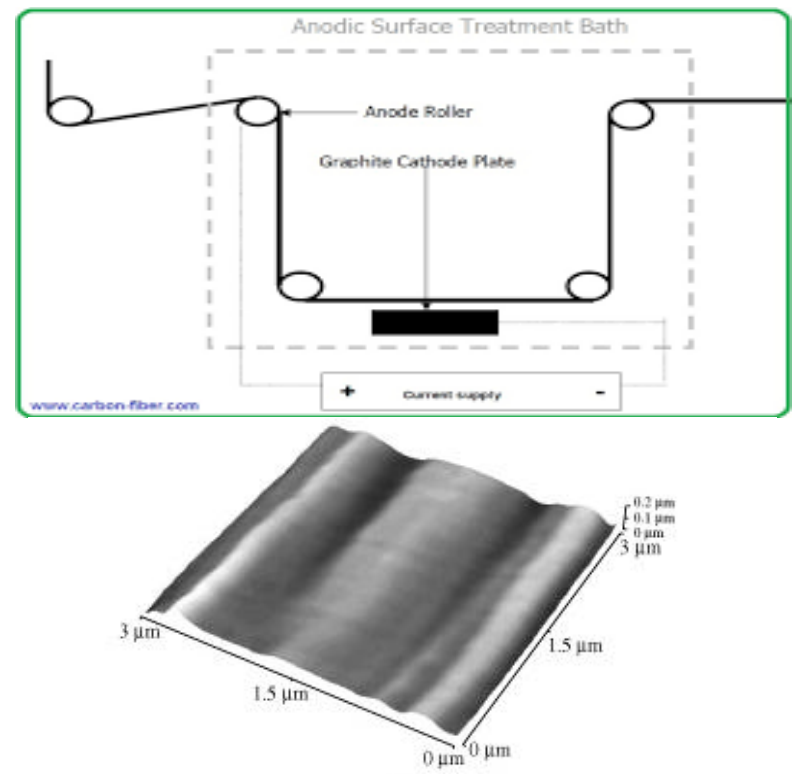

(b)

Fig. 2.4. Treating the surface

\subsection{Sizing}

After the surface treatment, the fibers are coated to protect them from damage during winding or weaving. This process is called sizing. Coating materials are chosen to be compatible with the adhesive used to form composite materials. Typical coating materials include epoxy, polyester, nylon, urethane, and others. The coated fibers are wound onto 


\section{UGC Approved Journal}

cylinders called bobbins. The bobbins are loaded into a spinning machine and the fibers are twisted into yarns of various sizes.

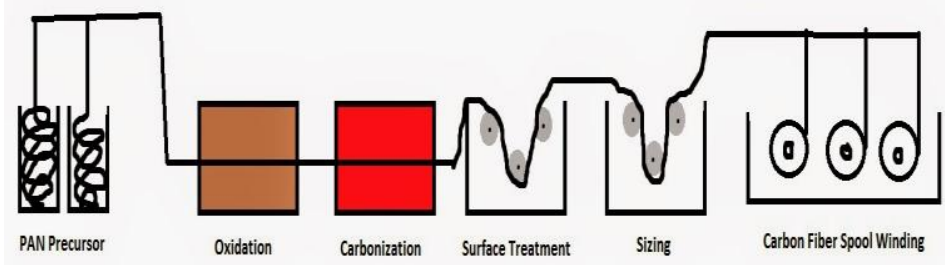

Fig . 2.5. Sizing

\section{CONCLUDING REMARKS}

\subsection{Advantages}

1. A unique and distinct appearance that's nearly impossible to replicate.

2. Excellent strength to weight ratio, compared to other materials.

3. Works well with other materials (fiber, plastics, metals, wood, concrete).

4. Suitable for complex contours and designs.

5. Superior fatigue properties.

6. High Stiffness.

7. High heat tolerances and resistance.

8. Flexible thermal and electrical properties.

9. Corrosion-resistance (with proper resins).

10. Varying classifications (tensile modulus) of strength. The strongest carbon fiber is 10x stronger and $5 \mathrm{x}$ lighter than steel. The strongest carbon fiber is $8 \mathrm{x}$ stronger and $1.5 \mathrm{x}$ lighter than aluminum.

\subsection{Limitations}

1. Carbon fiber will break or shatter when it's compressed, pushed beyond its strength capabilities or exposed to high impact. It will crack if hit by a hammer. Machining and holes can also create weak areas that may increase its likelihood of breaking.

2. The first disadvantage of using carbon fiber is that you need a mold if you want to make a decent product, making a mold is not always easy and you often need the help of some specialist.

3. Another disadvantage is the price of carbon fiber, it is very expensive. The material is very light and strong but you have to pay a big amount of money to be able to use it in your products.

4. Once a carbon structure is dint or cracked you cannot fix it like you can fix a steel structure. Once the structure is damaged the fibres are broken and the structure is probably not strong enough anymore. In most of the cases the structure had to be removed and thrown away and be replaced by an new one.

5. It is little bit harmful for the human body as it cause some form of cancer of the lungs.

6. Relative cost - carbon fiber is a high-quality material with a price to match. While prices have dropped significantly in the past five years, demand has not increased enough to increase the supply substantially. As a result, prices will likely remain the same for the near future.

\subsection{Applications}

1. Wind Turbines

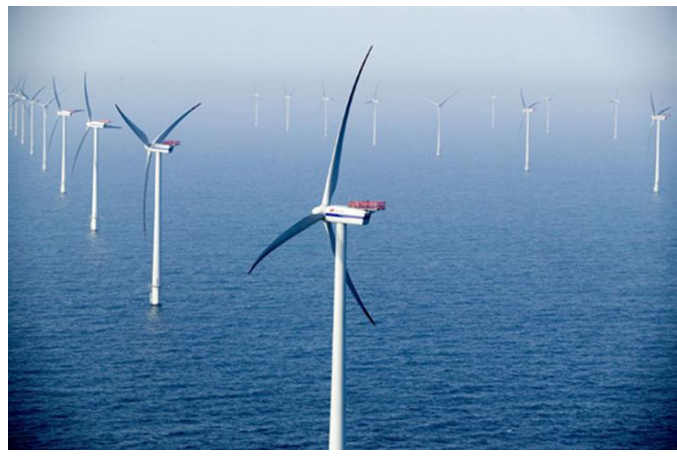


UGC Approved Journal

IARJSET

ISO 3297:2007 Certified

Vol. 4, Issue 7, July 2017

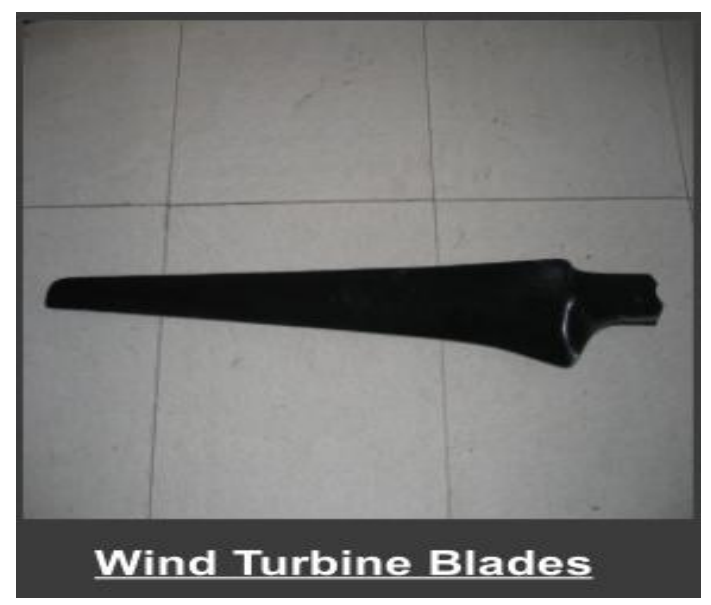

2. Sporting Goods

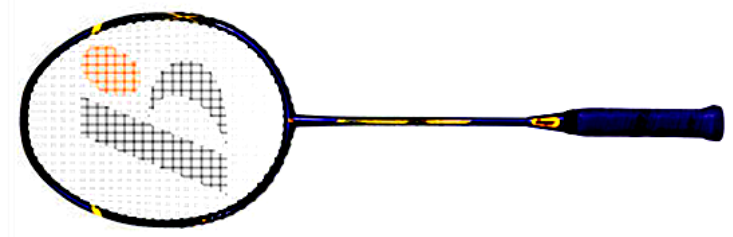

3. Golf Club Shafts

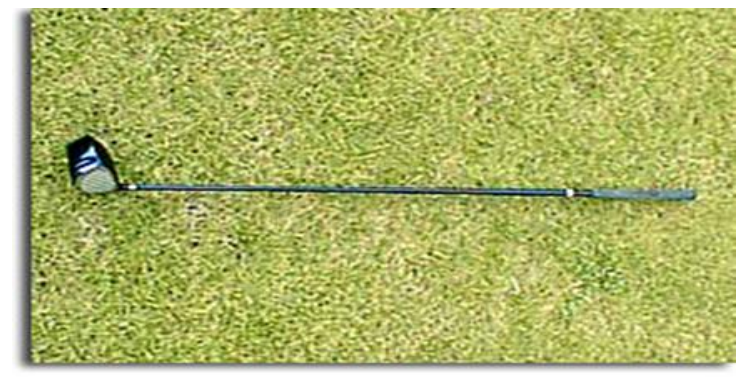

4. Bicycle Frames

5. Fishing Rods

6. Musical Instruments

7. Medical and Rehabilitation Parts

8. Elbow, Neck, and Knee Braces

9. Automobile Springs and Parts

10. Transportation and Vehicles

11. Automotive Industry

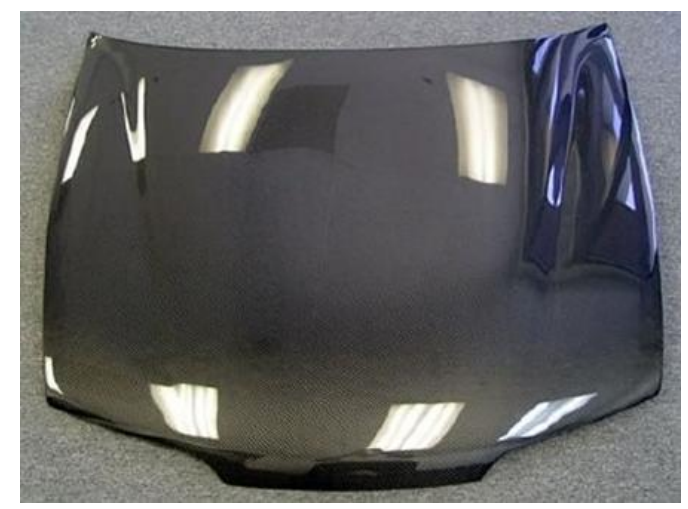

12. Racing Car Bodies

13. Automotive Repairs and Custom Parts 
14. Aftermarket Components for Automobiles

15. Replacement Parts for Trucks and Tractors

16. Boats and Nautical Products

17. Sailboat Masts

18. Aircraft and Spacecraft Parts

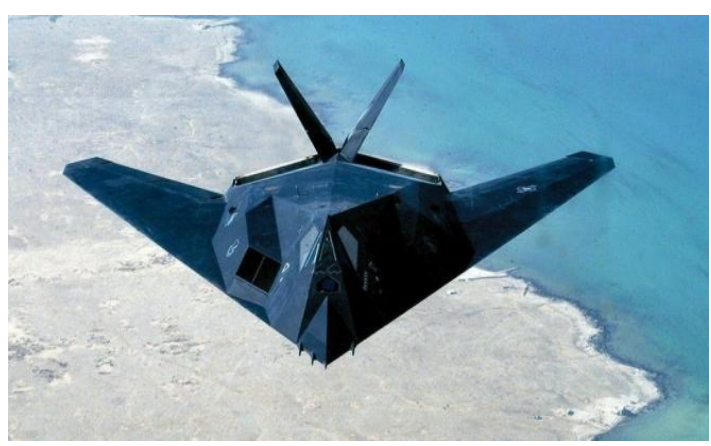

19. Civil Engineering

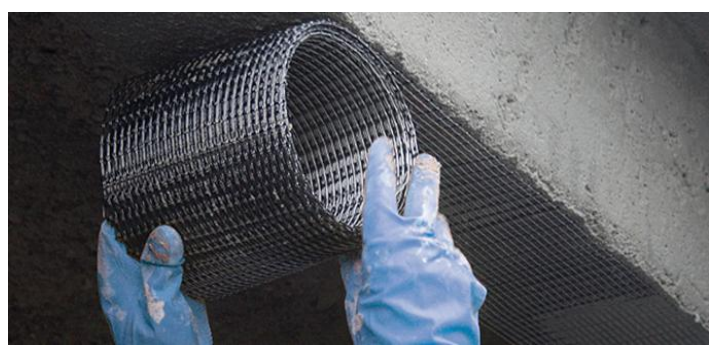

\section{Military}

\subsection{The Future Scope of Carbon Fiber}

Carbon fiber is already an important material in products across all markets and industries, and with new applications and uses discovered every year, the future of carbon fiber looks extremely bright. With its growth, carbon fiber and its composites offer great potential to the future of all markets and industries. With excellent strength to weight ratios and a long list of other benefits, carbon fiber's potential uses are currently growing in manufacturing, product design, energy conservation, natural resource conservation, the automotive industry, and more. Some key areas of natural resource, automotive, and commercial industry related growth include:

\section{Fuel Efficient Vehicles}

While carbon fiber is currently used in small batches of high performance vehicles and automobiles, the automotive industry is starting to increase their production of cars with carbon fiber features. Replacing steel components with carbon fiber would reduce the weight of most cars by $60 \%$, reducing fuel consumption by $30 \%$.

\section{Alternative Energy}

Carbon fiber and composites are commonly used to help build structures that produce alternate energy. Because it's light weight and strong, carbon fiber is often used in the production of wind turbines, compressed natural gas storage and transportation, and fuel cells.

\section{Oil Exploration}

Carbon fiber and its composites can also provide assistance with the creation of deep sea drilling platforms, drill pipes, and other oil exploration equipment. Incentives for using composites in oil exploration are substantial because of the corrosion resistance and light weight.

\section{Construction and Infrastructure}

Carbon fiber and its lightweight, but strong properties provide alternatives to traditional steel, aluminum and fiberglass materials, helping create lightweight, pre-cast concrete, as well as earthquake protection in buildings and structures of all types.

\section{Automotive Parts and Repairs}

Ultra lightweight carbon fiber composites offer great benefits to the automotive industry, including those related to fuel-economy and carbon-emissions. Originally confined to race cars, luxury cars, and show cars, carbon fiber 
composites may soon be found in more of our everyday vehicles. Repairs are currently available for all vehicles through custom auto repair shops like Malibu Collision Repair Center.

\section{REFERENCES}

1. F.P. Gerstle, IComposites," Encyclopedia of Polymer Science and Engineering, Wiley, New York, 1991

2. C. David Warren, "Carbon Fiber in Future Vehicles," SAMPE Journal, Vol. 37, No. 2, March/April 2001.

3. R. G. Boeman, N. L. Johnson, "Development of a Cost Competitive, Composite Intensive, Body-in-White," Proceedings of 2002 Future Car Congress, Arlington, Virginia, June 3-5, 2002

4. Carter ,F.C., and Paul,D.E. Material science and engineering. Ohio, ASM International, 1991351 pp.

5. Ashby, M.F., and Jones,D.R.H. Engineering materials-an introduction to their properties and applications. Oxford, pergamon Press, 1985 . 277 pp.

6. HarrisS,B. A perspective view of composite materials. Mat \& Design, vol 12, no. 5. 1991. pp. $259-271$.

7. Materials Edge, no. 50. Ju!. 1993, p. 4. PIGLIACAMPJI.,J. Organic fibers. Engineering materials handbook 1, Composites. Dostal, c.A., et al. (eds.). Ohio, A.S.M. International, 1989. 983 pp.

8. Amar Patnaik and Mahapatra S S (2009), "Study on Mechanical and Erosion Wear Behaviour of Hybrid Composites Using Taguchi Experimental Design", J. Materials and Design, Vol. 30, pp. 2791-2801.

9. Chauhan S, Kumar A, Patnaik A, Satapathy A and Singh I (2009), "Mechanical and Wear Characterization of GF Reinforced Vinyl Ester Resin Composites with Different Comonomers", J. Reinf. Plast. Compos, Vol. 28, pp. 2675-2684.

10. Folkes M J (1992), "Multi Component Polymer Systems", in Miles I S and Rostami S (Eds.), Longman Scientific and Technical: Essex, Chapter 8, UK.

11. Gururaja M N and Hari Rao A N (2012), “A Review on Recent Applications and Future Prospectus of Hybrid Composites", International Journal of Soft Computing and Engineering (IJSCE), Vol. 1, No. 6, pp. 352-355.

12. Manders P W and Bader M G (1981), "The Strength of Hybrid Glass/Carbon Fibre Composites: Part 1 Failure Strain Enhancement and Failure Mode", Journal of Materials Science, Vol. 16, pp. 2233-2245.

13. Marom G, Fischer S, Tuler F R and Wagner H D (1978), "Hybrid Effects in Composites: Conditions for Positive or Negative Effects versus Rule-of-Mixtures Behavior", Journal of Materials Science, Vol. 13, pp. 1419-1426.

14. Prabhakaran R T D, Madsen B, Toftegaard H and Markussen C M (2012), "Flexural Properties of Hybrid Natural Composite-Micromechanics and Experimental Assessment", Proceedings of 3rd Asian Conference on Mechanics of Functional Materials and Structures (ACMFMS), Vol. 1, pp. 469-472, Indian Institute of Technology, New Delhi.

15. Schwartz M M (1984), Composite Materials Handbook, McGraw-Hill, New York, USA.

16. Suresha B, Chandramohan G, Siddaramaiah P, Sampathkumaran and Seetharamu S (2007), "Mechanical and Three Body Abrasive Wear Behavior of 3-D Glass Fabric Reinforced Vinyl Ester Composites", J. Mater. Sci. Eng. (A), Vol. 443, pp. $285-291$.

17. Yosoyima R, Morimoto K and Suzuki T (1984), "The Reaction of Glass Fiber with Disocyanate and its Application", J. Appl. Polym. Sci., Vol. 29, pp. 671-679.

18. Yosoyima R, Morimoto K, Susuki T, Nakajima A and Ikada Y (1990), “Adhesion and Bonding in Composites”, Marcel Dekker Inc., New York, USA.

19. Zhang J, Chaisombat K, He S and Wang C H (2012), "Hybrid Composite Laminates Reinforced with Glass/Carbon Woven Fabrics for Light Weight Load Bearing Structures", Materials and Design, Vol. 36, pp. 75-80.

20. A. Dry, "The Development of the Carbon Fiber Industry," 42nd International SAMPE Symposium \& Exhibition, May 5 -8, 1997.

21. J. M. Corum, et al., "Durability-Based Design Properties of Reference Cross-ply Carbon-Fiber Composite," ORNL/TM-2000/322, Oak Ridge National Laboratory, April 2001.

22. H.O. Pierson, Handbook of Carbon, Graphite, Diamond and Fullerenes - Properties, Processing and Applications, William Andrew Publishing/Noyes, 1993.

23. S. Liu, "Carbon fiber contactor in polymer resistive position sensors", Proceedings of the 47th IEEE Holm Conference on Electrical Contacts, IEEE, 2001, pp.282-287.

24. J. Swift and S. Wallace, "Key aspects of the materials and processes associated with the cynthesis and use of distributed filament contacts from PAN fiber based composites", Proceedings of the 43rd IEEE Holm Conference on Electrical Contacts, IEEE, pp.190-200, 1997.

25. S.P. Shavkunov, M.I. Degtev, V.S. Korzanov, "A complex method of applying

26. aluminum to carbon fiber", Protection of Metals, Vol. 39, No. 4, July 2003, 385-388

27. V. S. Dergunova, V.S. Kilin, A.V. Sharova, V.I. Frolov and A.P. Nabatnikov, "Carbon fibers coated with zirconium pyronitride," Powder Metallurgy and Metal Ceramics, Vol. 15, No. 6, June 1976, pp. $422-425$ 